\section{Thyroid cancer after Chernobyl}

SIR - We would like to report a great increase in the frequency of thyroid cancer in children in Belarus, which commenced in 1990 and continues. Table 1 shows the incidence of thyroid cancer in children in the six regions of Belarus and Minsk City from 1986 to the seen that the overall incidence rose from an average of just four cases per year from 1986 to 1989 inclusive, to 55 in of the problem. end of the first half of 1992 . It can be

problems, and is placing great strains upon the health services of our new country. It also provides an opportunity, which we hope will not be repeated, to study the consequences of major exposure of a population to isotopes of iodine from fallout. We are collaborating with several international groups and are preparing detailed reports of various aspects

We believe that the only realistic

\begin{tabular}{lccccccrr}
\hline & TABLE 1 & \multicolumn{7}{c}{ Incidence of thyroid cancer in children in Belarus } \\
\hline $\begin{array}{l}\text { Region of } \\
\text { Belarus }\end{array}$ & 1986 & 1987 & 1988 & 1989 & 1990 & 1991 & $1992^{*}$ & Tota \\
Brest & 0 & 0 & 1 & 1 & 6 & 5 & 5 & 18 \\
Vitebsk & 0 & 0 & 0 & 0 & 1 & 3 & 0 & 4 \\
Gomel & 1 & 2 & 1 & 2 & 14 & 38 & 13 & 71 \\
Grodno & 1 & 1 & 1 & 2 & 0 & 2 & 6 & 13 \\
Minsk & 0 & 1 & 1 & 1 & 1 & 4 & 4 & 12 \\
Mogilev & 0 & 0 & 0 & 0 & 2 & 1 & 1 & 4 \\
Minsk City & 0 & 0 & 1 & 0 & 5 & 2 & 1 & 9 \\
Total & $\mathbf{2}$ & $\mathbf{4}$ & $\mathbf{5}$ & $\mathbf{6}$ & $\mathbf{2 9}$ & $\mathbf{5 5}$ & $\mathbf{3 0}$ & $\mathbf{1 3 1}$ \\
\hline
\end{tabular}

* Six months of 1992.

1991 and is projected to be not less than 60 in 1992. This increase is not uniformly distributed across the country: for example, there is no significant increase in Mogilev, Minsk City or Vitebsk. By far the greatest increase is seen in the Gomel region, from one or two cases per year to 38 in 1991, and a less obvious increase is seen in the Brest and Grodno regions.

The Gomel region lies immediately to the north of Chernobyl and is known to have received a high level of radioactivity as fallout after the breakdown of reactor number 4 on 26 April 1986. The plume passed first over the Gomel region in the first few hours after the major release of radioactivity, and then over the Brest and Grodno regions. The fallout contained large amounts of ${ }^{131} \mathrm{I}$ and significant amounts of the shortlived isotopes of iodine, although these were too short-lived to be measured.

We have classified the tumours according to the World Health Organisation classification (2nd edn) and find that virtually all are papillary carcinomas (128 of 131). They are, however, relatively aggressive, as can be seen from Table 2. Fifty-five of the 131 cases showed direct extension to the perithyroid tissues and six distant metastases, mostly in the lungs. It can be seen that only about 23 per cent were less than 1 $\mathrm{cm}$ in diameter. One of the children has died at seven years of age and ten others are seriously ill.

The occurrence of this increase in thyroid cancer in children within a few years of exposure to radioactive isotopes of iodine is unexpected, but real. It poses both humanitarian and scientific explanation for the increase in the fredirect consequence of the accident at Chernobyl.

Vasili S. Kazakov

Ministry of Health of Belarus,

House of Government,

220010 Minsk, Belarus

Evgeni P. Demidchik

Thyroid Tumour Centre,

F. Skorinay Avenue 64 ,

220600 Minsk, Belarus

Larisa N. Astakhova

Radiation Medicine Institute,

Masherov Avenue 23,

220600 Minsk, Belarus

SIR - We have recently visited Belarus under the auspices of the WHO regional office for Europe and the Swiss government, and have had the opportunity to see some of the children with thyroid cancer, to study the pathology of the cases and to examine the relevant data. quency of thyroid cancer is that it is a
We examined 11 children who had had operations for thyroid carcinoma and were now hospitalized for post-operative management or evaluation of metastatic disease. We were shown the complete records for these patients, including $\mathrm{X}$ rays and echograms before and after treatment. All were diagnosed during the past 3 years, eight having been living in the Gomel region at the time of the Chernobyl accident and two in the Brest region. The age at diagnosis of the six females and five males was between 4 and 13 years of age; the youngest was born two days after the accident.

We have studied the histological slides from 104 cases of children from Belarus in whom the diagnosis of thyroid carcinoma had been made since January 1989. We agree both with the diagnosis of malignancy and of the type of malignancy in 102 of the cases. We also examined the data on the incidence of thyroid carcinoma in Belarus. There is a marked increase in frequency from 1990 onwards over the average for the years from 1986 to 1990 . This increase started only 4 years after the Chernobyl accident, a surprisingly short time by comparison with studies of thyroid carcinoma that have followed exposure to external radiation in infants $\mathrm{s}^{1,2}$. Of the children with thyroid carcinoma in Belarus since 1990, the eight youngest at exposure were in utero, but were more than 3 months of fetal age at the time of Chernobyl. The fetal thyroid is known to start concentrating iodine at 12-14 weeks of gestation.

We do not believe that increased ascertainment of cases could have played more than a minor role in the recorded incidence of thyroid carcinoma. The proportion of resected nodules that are malignant is high and the type of tumour is aggressive. The ratio of thyroid carcinoma in children to that in adults has increased dramatically, although there are now signs that the incidence in patients over the age of 15 is beginning to increase. The rate is greatly in excess of the reported incidence of this disease

TABLE 2 Extent of spread (TNM classification) of thyroid cancer in children

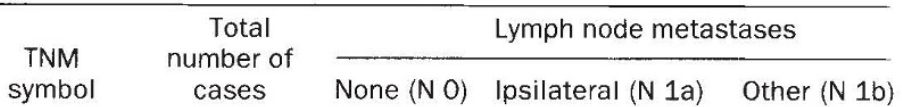

\begin{tabular}{lrrrrr}
$\begin{array}{l}\text { Tumour size } \\
\quad 1 \mathrm{~cm}\end{array}$ & T1 & 30 & 17 & 10 & 3 \\
$\begin{array}{l}1-4 \mathrm{~cm} \\
>4 \mathrm{~cm}\end{array}$ & T2 & 33 & 17 & 8 & 8 \\
$\begin{array}{l}\text { Extending } \\
\text { to surrounding }\end{array}$ & T3 & 7 & 3 & 4 & 0 \\
$\begin{array}{l}\text { tissues } \\
\text { Distant }\end{array}$ & $\mathrm{T} 4$ & 55 & 14 & 18 & 23 \\
metastases & $\mathrm{M} 1$ & 6 & 1 & 1 & 4 \\
Total & & $\mathbf{1 3 1}$ & $\mathbf{5 2}$ & $\mathbf{4 1}$ & $\mathbf{3 8}$ \\
\hline
\end{tabular}

Classification as in TNM Atlas 3rd edn, eds Spiessl, B. et al., UICC (Springer, Berlin, 1990). 